\title{
Thank you to Via Medica after nine years: the Editor's comments
}

After nine years of collaboration with the publishing house Via Medica, the Board of the Polish Cardiac Society has made a decision that Medycyna Praktyczna will be the new publisher of the official journal of the Society, Kardiologia Polska (Polish Heart Journal), from April 2019 to March 2021.

The past nine years have been the time of several beneficial changes focused on increasing the standing of the journal with a continued support of Via Medica. Over this time period, the Impact Factor (IF) of Kardiologia Polska has risen from 0.5 in 2011 to 1.21 in 2017, with the highest value calculated in 2016, i.e. 1.34.

The publisher helped us meet our goals of enhanced scientific communication by improving the editorial system and increasing the journal's visibility. The team, in particular Ms. Joanna Niezgoda, was enthusiastic, flexible, and creative, ready to provide rapid, thoughtful feedback, and do everything to enhance the quality of the articles.

It has been 15 months since I embarked on this exciting adventure, by taking over the role of Editor-in-Chief of Kardiologia Polska from Professor Krzysztof J. Filipiak. With the support of Via Medica we have come a long way in a short space of time and achieved a lot during the last challenging year.

On the $1^{\text {st }}$ of January 2018, as many as 69 accepted papers awaited publication and 81 other manuscripts were at various stages of the review process (the oldest submitted in January 2017 — sic!). The mean time since acceptance to publication in print was four months and the mean time since submission to final publication was seven months (up to more than one year).

Since hard data speak loudly, I would like to point out the following changes that have been introduced:

- rapid editorial turnaround - in the first months of 2019, 22 papers were awaiting publication and 23 other manuscripts were under review; the mean time since acceptance to publication in print decreased to two months and the mean time since submission to final publication to three and a half months;

- review articles written by leading experts from abroad published in each issue;

- editorials containing comments on the selected original articles, written by experts;

- short communications to present preliminary data or case series;

- two-stage linguistic correction;

— professional antiplagiarism tool to assess each submitted article (iThenticate);

- Kardiologia Polska on social media, Facebook and Twitter;

- finally, the first financial support from the Ministry of Science and Higher Education to improve the quality of articles published in the journal.

Last but not least, we are pleased to announce that the 2018 IF of Kardiologia Polska is estimated to be 1.62, which denotes an increase by more than $20 \%$ as compared to the latest 2017 IF of 1.21 . We would like to thank all Authors, Associate Editors, Editorial Board Members, and Reviewers, who are making all this possible.

We express our enormous gratitude to Via Medica, to all editorial office members and staff. Their efforts have contributed to the continued success of the journal. The path ahead with a new publisher is certainly full of challenges, however we hope that we can build further on this success. Our goal is to bring our journal among the top quality European publications in the field of cardiology and to promote Polish cardiovascular research.

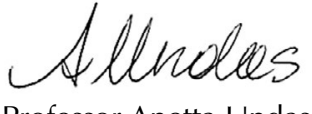

Professor Anetta Undas Editor-in-Chief 
